\title{
Sensacionalismo, justicia y gobierno en la prensa neogranadina, |830- 1858
}

Gilberto Enrique Parada García'

Universidad del Tolima

\section{Resumen}

El tema de este análisis es la historia de la prensa que se publicó durante la República de Nueva Granada ( 830 - 1858). El trabajo pretende señalar el lugar que aquella ocupó en la vida pública de los neogranadinos. Para tal fin, se priorizan los casos en los cuales la prensa registró algunos eventos críticos del ámbito de la política, de ahí que se concluye que los periódicos cumplieron tres funciones esenciales. De una parte, fueron una herramienta pedagógica de los gobiernos para inculcar en los lectores una cultura del republicanismo. En segundo lugar, sirvieron como un amplificador del caos; por último se convirtieron en el escenario extrajurídico para resolver litigios durante las guerras.

Palabras clave: Historia de la prensa, política, sensacionalismo, justicia, guerra.

I Historiador de la Universidad Nacional de Colombia, sede Bogotá. Magíster en Historia con énfasis en la línea de investigación en Estado, Nación y Guerra de la Universidad Nacional de Colombia, sede Bogotá. Doctorando de la Pontificia Universidad Javeriana de Bogotá, en el programa de Doctorado en Ciencias Jurídicas. Ha sido profesor de las Universidades Nacional de Colombia, Antonio Nariño y Fundación Universidad Autónoma de Colombia, también se ha desempeñado como docente en propiedad de la Secretaría de Educación del Distrito Capital (SED). En la actualidad es profesor asociado del Departamento de Ciencias Sociales y Jurídicas de la Universidad del Tolima, en Ibagué. Dirección electrónica: geparadag@gmail.com 


\title{
Sensationalism, justice and governance in the Nueva Granada press, 1830-1858
}

\begin{abstract}
The subject of this analysis is the history of the press which was published during the Republic of New Granada (1830-1858). The work aims to point out the place that occupied in the public life of the New Granada people. For this purpose, are prioritized the cases in which the press recorded some critical of the scope of the policy events, hence, it is concluded that newspapers met three essential functions. First, were an educational tool of Governments to inculcate a culture of republicanism in readers. Second, they served as an amplifier of chaos; Finally became the extra-legal scenario to resolve disputes during the wars.
\end{abstract}

Key words: History of the press, political, sensationalism, justice, war.

\section{Sensacionalismo, justiça e governo nos jornais neogranadinos, 1830-1858.}

\section{Resumo:}

O tema desta análise é a história dos jornais que foram publicados durantes a República de Nueva Granada ( 1830- |858). O trabalho pretende sinalizar o lugar que aqueles ocuparam na vida pública dos neogranadinos. Para tal finalidade, se priorizam os casos nos quais os jornais registraram alguns eventos críticos do âmbito da política, daí se conclui que os jornais cumpriram três funções essenciais. De uma parte, foram ferramenta pedagógica dos governos para inculcar nos leitores uma cultura do republicanismo. No segundo termo, serviram como um amplificador do caos; por último, se converteram no cenário extrajurídico para resolver litígios durante as guerras.

Palavras chave: História dos jornais, política, sensacionalismo, justiça, guerra.

\section{Introducción}

Este artículo tiene como objetivo analizar cómo la prensa se convirtió en un espacio del debate político, jurídico y social que tendió a modificar las condiciones imperantes en la República de Nueva Granada. De modo que fue la portavoz de diversos sectores sociales, preferiblemente de la élite, y que configuraron sus lealtades políticas ya fuese al partido liberal o al conservador. Los articulistas (periodistas) de Nueva Granada, emplearon fórmulas argumentativas y la violencia en la escritura para exagerar eventos y sucesos cotidianos en pos de adelantar reformas sociales: instauración de un sistema penal, el inicio de la policía republicana, la focalización de la pobreza, entre otras.

La propuesta metodológica pone especial atención a las reiteraciones en la prensa; el rastreo de estrategias de comunicación tales como el sensacionalismo, el chisme y el rumor que se ponen 
en contra cara con otra serie de fuentes de tipo legal. La prensa es estudiada a la luz de las leyes del período que tienen que ver con la libertad de opinión y las medidas legales de orden público que se toman en la época, durante las crisis sociales y las guerras.

Algunos resultados del análisis propuesto indican que la prensa fue determinante para implementar medidas penales, policivas y políticas, especialmente las que se desarrollaron en la capital del Estado, en Bogotá, durante la primera mitad del siglo XIX. Además, dada la importancia de la prensa para convencer al público, esta se convirtió en un estrado extra-jurídico al que se acudió para solucionar litigios. La prensa exageró la dimensión de conflictos sociales y políticos que desencadenaron guerras civiles y formó, en la opinión pública, una idea tergiversada de la realidad. Para lograr este cometido, estudiar la prensa granadina, el ensayo se articula en cuatro apartados: el primero de ellos apunta a brindar un panorama general de las condiciones de vida de los neogranadinos, la situación económica y cultural, pero sobre manera destaca las vicisitudes políticas del país en el periodo estudiado. El siguiente apartado se encarga de resumir las estrategias argumentativas amparadas en el sensacionalismo, la simulación, el chisme y el rumor. Luego este artículo aporta algunas ideas concernientes al uso instrumental de la prensa con fines pedagógicos: alcanzar consensos en torno al carácter civilista del país. Finalmente, destaca cómo la prensa neogranadina asume las funciones propias de un estrado judicial para recomponer situaciones en las cuales la honra y el honor de los granadinos, preferiblemente de la élite, hubiesen sido menoscabados por el aparato estatal de justicia durante la guerra.

\section{El contexto}

Durante el período de la historia colombiana que comprende casi tres décadas, desde 1830 a I858, se puso en marcha un proyecto de Estado de corte centralista y en muchos aspectos conservador, pero necesariamente republicano. Uno de los soportes de este régimen fue el sentimiento de reconciliación con el pasado colonial español que quedó plasmado en el nombre del país, ya que dejó de llamarse Colombia para convertirse en la República de Nueva Granada, este suceso no es una simple anécdota toponímica, puesto que expresa una explicación de su tiempo al fracaso del ideario independentista y revolucionario liberal. ${ }^{2}$ Dos matices del período -que persisten en la historia nacional-, se refieren de una parte al semblante civilista de la política en Colombia y en segundo término, lo hacen a la apatía de la sociedad política por los gobiernos de corte draconiano, la prensa neogranadina registró con ahínco los dos matices desde 1830.

2 Dos estudios pueden guiar este argumento. De una parte, Aimer Granados analizó la toponimia republicana del siglo XIX y señala: "En esto hay que señalar que Nueva Granada como nombre -pero especialmente como entidad política, territorial e históricatuvo mayor fuerza que su rival Colombia, al menos en cuanto al contexto de la transición colonial a los tiempos republicanos". José Carlos Chiriamonte, Carlos Marichal y Aimer Granados. Crear la Nación. Los nombres de América Latina. (Buenos Aires: Editorial Sudamericana, 2008): 194. De otra parte, es reconocible una tendencia centralista neoborbónica que se asume en Nueva Granada, en la política fiscal, luego de la separación de Venezuela y Ecuador. José Joaquín Pinto Bernal, Entre Colonia y República. Fiscalidad en Ecuador, Colombia y Venezuela, 1780-1845. (Bogotá: Universidad Nacional de Colombia, 20 I4). Tesis doctoral en historia. 
No obstante, el reformismo liberal se impuso lentamente durante esos años, llegando con ímpetu al medio día del siglo XIX para moldear un nuevo Estado federal. Las innovaciones fueron cotejadas por la historiografía liberal a fín de presentarlas como fenómenos revolucionarios aunque su alcance transformador fue irrelevante. La historiografía conservadora no ahorró críticas para afirmar que las reformas iban contra la naturaleza tranquila y sosegada del pueblo que se vio alterada por ideologías extrañas. De manera que el saldo que se puede sacar del espíritu reformista es mínimo: la manumisión de esclavos, una serie de libertades individuales y los intentos de construir un estado secular, esta última reforma fue una causa de las hostilidades entre liberales y conservadores en el transcurrir de la segunda mitad del siglo XIX y la primera mitad del XX.

Entonces, la primera mitad del siglo XIX enseña que la Nueva Granada es un país que depende de la exportación aurífera que cae en picada; el gobierno intenta mantener un sistema de protección a la débil producción local -paralelo a esta circunstancia de la economía es evidente que el contrabando caló profundamente en la sociedad neogranadina, ${ }^{3}$ además el crecimiento económico, a excepción de la producción tabacalera de 1845, fue lento durante el periodo. Más aún, en Bogotá, en la década de 1830 inició un fallido intento de industrialización; antes de 1840 ya habían cerrado las cuatro fábricas de la ciudad.

Las condiciones de la vida urbana de los granadinos no se parecían a las de la vida cosmopolita de las grandes ciudades europeas. Bogotá, la capital contaba con unos 20.000 habitantes en 1820,4 los pobres en la ciudad en su mayoría indios y mestizos se ubicaron en los cerros de la ciudad, habitaban casas llamadas bohíos con tejados de paja y en el mejor de los casos dormían en las trastiendas. Según las descripciones de la prensa decimonónica, la ciudad tenía un sistema de acueducto muy precario, casi inexistente que se reducía a unas pocas fuentes de agua; el desaseo, la inseguridad, las epidemias y la escasa infraestructura vial eran muy frecuentes en la Bogotá del siglo XIX. Otras ciudades colombianas registraban un patrón similar al de Bogotá. De modo general la esperanza de vida de los neogranadinos, durante la primera mitad del siglo XIX, fue muy baja. ${ }^{5}$ Se estima que un granadino vivía en promedio 26,5 años; 25,2 años para los hombres; 26,8 años para las mujeres. ${ }^{6}$

3 Para comprender el fenómeno del contrabando en la historia de Colombia en el siglo XIX se puede consultar a: Laurent, Muriel. Contrabando en Colombia en el siglo XIx. (Bogotá: Universidad de los Andes, 2008)

4 "Entre 1830 y 1835, los flujos migratorios resultaron en una serie de presiones demográficas sobre la ciudad, lo que incidió en que las relaciones sociales de los bogotanos — propias de los lugares públicos_-, tales como los intercambios económicos y las confrontaciones socio raciales, adquirieran una magnitud mayor". Gilberto Enrique Parada García. "La retórica del miedo en la prensa bogotana de 1834". Historia Critica 36 (Jul-dic, 2008), pág. 65.

5 Los cálculos de la masa poblacional para la Nueva Granada se basan en los censos, el de 1835 habla de una población estimada de 1.433.500 habitantes, en tanto que en 1843 el cálculo estimado llegó a 1.643,500. En I85 I dicha cifra se estimó en 1.865. I00 habitantes. Los variables que afectan los cálculos son las guerras, la natalidad y la mortalidad infantil, las enfermedades y la desnutrición; además el reordenamiento del territorio en provincias y después en estados alteró la medición demográfica en la Nueva Granada. Meisel Roca, Adolfo y María Teresa Ramírez. Economía colombiana del siglo xIx. (Bogotá: FCE / Banco de la República, 2010) págs.384-385.

6 MEISEL ROCA, Adolfo y María Teresa Ramírez. Economía colombiana del siglo XIx. (Bogotá: FCE / Banco de la República, 20 I0) pág. 395. 
La situación en el campo colombiano no era muy distinta. Colombia en el siglo XIX era una sociedad rural; los centros de la vida campesina que convocaban a hombres y mujeres por igual fueron la plaza de mercado y la parroquia. Los campesinos trabajaban en condición de inquilinos en las grandes haciendas de la cordillera oriental de los andes colombianos, por tanto estaban a merced de relaciones de producción pre-capitalistas, también estaban sometidos a chantajes laborales y padecieron otras formas de extorsión por parte de los hacendados y capataces.

En los municipios, las formas de sociabilidad campesina estaban relacionadas con los intercambios económicos en el mercado; los intercambios simbólicos se efectuaban en las liturgias y en las peregrinaciones; los intercambios afectivos se realizaban en las tiendas en las que compartían indios y mestizos, hombres y mujeres, tanto sus favores sexuales como sus gustos etílicos por la chicha. ${ }^{7}$

La década de 1830 inicia con hechos muy graves que fueron comunicados por la prensa. El asesinato del Mariscal de Sucre, el ostracismo de Simón Bolívar y su muerte y la disolución del Estado colombiano (la Gran Colombia). Estos hechos sembraron la confusión y el caos en el ejército que se vio sometido a una reducción considerable en el número de sus tropas.

A pesar de las circunstancias, cundía un aire de esperanza en el que la reunificación de los tres Estados que integraron la República de Colombia se diera nuevamente. Los seguidores de Bolívar esperaban que su sucesor, Rafael Urdaneta, exclamara en el Congreso: "he conjurado la tempestad

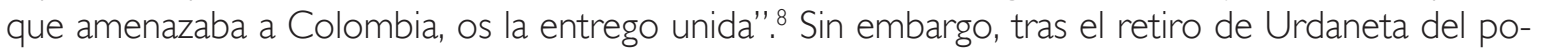
der, la aversión mutua entre los cuadros de los mandos militares venezolanos y los mandos civiles colombianos se agudizó.

El primer gobierno de la República de Nueva Granada, recién instituida -el del presidente Francisco de Paula Santander, enfrentó la crisis política y lo hizo expulsando a una serie de militares venezolanos, a la vez que promulgó normas para garantizar las libertades individuales, incluida la inviolabilidad de la correspondencia.

Al finalizar la década se presentó la primera guerra civil luego de la independencia. La Guerra de los de Supremos fue el resultado de las luchas entre las facciones políticas que se disputaron la cuota burocrática del Estado; a la vez la confrontación armada estaba inspirada en la defensa de la institución eclesiástica, este último factor desencadenó la lucha. Una medida presidencial ordenaba el cierre de los conventos que no reuniesen un mínimo de clérigos. Las reacciones surgieron en el sur del país, en la ciudad del Pasto. El comandante de la expedición del gobierno les dio un parte a los pastusos, en la que acusaba a la clerecía de haber iniciado la guerra:

$7 \quad$ El historiador Hermes Tovar, apunta cómo las tiendas a finales de la era colonial se constituyeron en los sitios para el encuentro amoroso ilegítimo. Las denuncias de los amancebados iniciaban ante las autoridades a través del chisme y el rumor. Hermes Tovar Pinzón. La batalla de los sentidos. Infidelidad, adulterio y concubinato a fines de la colonia. Bogotá: Universidad de los Andes, 2012) págs. 33,34.

8 El Duende, (s.d.) 
Los frailes $[\ldots]$ han abierto violentamente las puertas de las cárceles, para que toda clase de criminales tomase las armas contra el gobierno; han saqueado los templos; han hecho robar y asesinar a los ciudadanos pacíficos; hasta el sexo delicado ha sido víctima de su brutal ferocidad, jy todo esto se ha hecho en nombre la religión! Vosotros sois testigos de tal desenfreno; y es preciso que proclaméis: NO MÁS FRAILES; NO MÁS FANATISMO.

La Guerra de los Supremos consolidó las filiaciones de los partidos liberal y conservador, ${ }^{10}$ también enseñó cuán escindida y frágil era la unidad nacional, se estima el número de bajas producidas por esta guerra en 7.100 muertes. " Esta guerra demuestra que las identidades partidistas, auspiciadas por vínculos clientelistas, valdrían mucho más que los sentimientos de pertenencia a una unidad nacional o patriótica. ${ }^{2}$ Pero no fue el único evento bélico que padeció la Nueva Granada. En I 85 I estalló otra contienda armada por la puesta en marcha de la ley de manumisión de esclavos, las oligarquías del occidente reaccionaron en contra de la medida de libertad tomada por el poder central; en I854 ocurrió el golpe militar del general José María Melo. Un grupo de soldados amotinados entró a la ciudad de Bogotá y con la ayuda de un sector del artesanado proclamó el gobierno militar de Melo. Casi inmediatamente, una coalición constitucionalista marchó contra los golpistas, luego de varios enfrentamientos se restableció el gobierno civilista.

Una novela histórica, escrita en el siglo XIX por Bernardino Torres Torrente, reseñaba el interregno de 1849 a I85 I, y contextualiza los años que se vivieron luego de la Guerra de los Supremos, así:

Vencidos los republicanos [el autor hace referencia a los liberales seguidores de Santander -ya fallecido- y de José María Obando], subió al solio presidencial el general Pedro Alcántara Herrán; durante su administración se dictaron varias providencias con el objeto de establecer el gobierno fuerte y vigoroso en que soñó el general Bolívar; se solicitó de Inglaterra un protectorado a fin de afianzar el poder, bajo el especioso pretexto de asegurar la deuda exterior, a lo que se negó el gabinete de San James, con el carácter de honradez que le era propio; se sancionó la tiránica medida de leyes de seguridad, y se dio al país una nueva constitución (la de 1843), antiliberal en esencia. ${ }^{13}$

9 Pedro Alcántara Herrán. Revolución de ideas, Bogotá, Imprenta de N. Gómez, 1839.

10 Si bien es cierto que los partidos políticos colombianos se remontan a mediados del siglo xix; pues el liberal aparece en 1848 y el conservador a 1849, también lo es que sus elementos constitutivos, bien sean de clase o de filiación, están presentes en la década de 1830. Respecto al origen de los partidos se pueden consultar: Germán Colmenares, Partidos políticos y clases sociales. (Bogotá: Ediciones los comuneros, 1984); Helen Delpar. Rojos contra azules. El partido liberal en la política colombiana, 1863 1899. (Bogotá: Procultura, 1994) y Gerardo Molina, Las ideas liberales en Colombia, I849-1914. Tomo I, (Bogotá: Universidad Nacional de Colombia, 1970).

II Meisel Roca, Adolfo y María Teresa Ramírez. Economía colombiana del siglo xIx. (Bogotá: FCE / Banco de la República, 20 I0), pág. 379.

12 González Fernán E. . Partidos, guerra e Iglesia en la construcción del Estado Nación en Colombia (I 830-1 900). (Medellín: La Carreta, 2006), pág. 35.

13 Torres Bernardino Torrente, Sombras y misterios, o los embozados. (Bogotá: Imprenta de Francisco Torres Amaya, | 859), pág. I4. 
La ausencia de un liderazgo y la debilidad de las instituciones políticas neogranadinas, contrastaban con la proliferación de la prensa panfletaria, las hojas sueltas y los líbelos difamatorios se multiplicaban en las calles, también circulaban en los mercados y en las tiendas. Los sectores reaccionarios acusaban a la ley de libertad de imprenta de generar los abusos en la prensa. En 1822 se dio un lapso de censura de prensa, y el gobierno la justificó por ir en contra de la unión del país, de la moral y del honor ciudadano. Un año más tarde fueron nombrados 24 jueces de hecho que conocerían las causas de abuso de la libertad de imprenta.

De acuerdo con David Bushnell, la prensa colombiana en sus inicios vivió una fase panfletaria en la que difícilmente pueden ser identificados periódicos como tal. ${ }^{14}$ Es por esto que la forma de los periódicos neogranadinos conservó el carácter de los panfletos. El cuerpo de algunos periódicos se limitaba a unas cuantas hojas, cuya calidad era bastante cuestionable bien fuera por el número de imprentas, generalmente localizadas en Bogotá, o por la misma calidad y por el costo del papel en que se imprimían. ${ }^{15}$ Solamente unos pocos títulos contaban con el apoyo estatal y por tanto se convertían en el eco de los gobiernos. Otros dependían de las suscripciones, que resultaban muy pocas o los publicistas tenían que acudir a las dádivas de los partidos y de los gremios. Para 1837 se estableció que, los periódicos oficiales se debían fundar uno en cada una de las provincias de Nueva Granada, se financiarían con las ventas de los periódicos y el déficit que resultase, se enmendaría a través del tesoro nacional. ${ }^{16}$

Las estadísticas dicen que el número de periódicos que circularon en la Nueva Granada fue considerable, si se piensa en los datos sobre la alfabetización y el número total de la población. Sin tener en cuenta el número de ejemplares de cada una de las publicaciones periódicas, en el año de I 853 circularon diez periódicos en Bogotá, dos eran de carácter oficial. Cuatro circulaban en Cartagena, dos lo hicieron en Panamá, dos en Medellín, uno en Mariquita y otro en Mompox. En total para toda la República fue de 24 periódicos ese año, entre los que sobresalieron El Neogranadino, La Gaceta Oficial, El Catolicismo, El Coco, La Patria, La Voz del Tolima y otros más. ${ }^{17}$

El contenido de algunos periódicos imitaba las características de la prensa inglesa o norteamericana; otros periódicos panfletarios acudían a un lenguaje bucólico, escritos a la manera de los salmos o de los catecismos católicos incluían cuestionarios y responsas -consistían en el diálogo entre un iniciado y su maestro o entre un recién llegado y un vecino de vieja data- y para no dar pie a la crítica en sus argumentos incitaban a seguir un profundo sentido moralizante. En tanto que la prensa bogotana durante el régimen de la "Gran Colombia" era en su mayoría liberal, la prensa conservadora era pro-clerical y católica. La primera se asemejaba más a una prensa periódica, otra cosa ocurría con

I4 Bushnell David. Ensayos de historia política de Colombia, siglos XIx y xx. (Medellín: La Carreta, 2005) pág. 27.

I5 Apunta Bushnell: "Así y todo, las imprentas todavía no eran numerosas, ni impresionantes en su tamaño y calidad. El surtido de papel periódico tampoco era adecuado, y las fluctuaciones dela guerra civil y extranjera restringían inevitablemente el crecimiento de la prensa periódica". Bushnell, pág. 29.

16 El Argos, Bogotá, (s.d) No. 43, nov. 26 de 1837.

17 El Repertorio, Bogotá, No. 44, diciembre 3 de 1853: pág. 184 
la prensa conservadora que se asemejaba más la prensa de folletos. Luego del experimento estatal colombiano, la prensa granadina fue más crítica del gobierno gracias a la política de libertad de imprenta, así lo comenta Eduardo Posada Carbó:

Disuelta la unión con Venezuela y Ecuador, el periodismo siguió evolucionando, en la Nueva Granada, en términos generales, sobre esas bases santanderistas. En las elecciones presidenciales de 1836-7, sobresalía una forma de prensa predominantemente política, dirigida a la incipiente "opinión pública" -expresión que aparecía con cierta frecuencia en los periódicos de la época-. Cualquier intento conservador de restringir la libertad de imprenta, tras la Constitución centralista de 1843, se tropezó con el nuevo impulso liberal que en el país cobró nuevos bríos, sobre todo después del impacto de las revoluciones europeas del $48 .{ }^{18}$

En este paisaje controversial de la política neogranadina, la prensa se convertía en una expresión de la voz popular. Puesto que el discurso político acudiría permanentemente a la autoridad de la opinión pública, los publicistas - periodistas- bogotanos del siglo XIX constantemente argumentaron que la prensa acogería a todos los ciudadanos sin algún distingo, un periódico bogotano lo puso en los siguientes términos: "[...] nuestro lenguaje será igual al que usan estos picarillos, generalmente en el ejército: un chiste, un refrán, una burla, un cuentecito; y con excepción del artículo propiamente editorial, todo será trivial y pasajero, pero juicioso y ameno". ${ }^{9}$ El encabezado de otra publicación periódica, El Sastre, se refería a una suerte de "periódico-manía" que en la época de la Guerra de los Supremos se apoyaba en el conocimiento de intelectuales y políticos; por el contrario, El Sastre acudía a la opinión popular supuestamente por ser más justa con la verdad, así lo expresó el periódico bogotano a través de los siguientes versos:

$$
\begin{gathered}
\text { ¿Pues por qué de la ocasión } \\
\text { No se debe aprovechar } \\
\text { Y dar una felpa a tanto } \\
\text { Literato charlatán? } \\
\text { Tantos eruditos hueros } \\
\text { Cuyo talento venal }
\end{gathered}
$$

Nos da en menudos las ciencias

Que no supieron jamás. ${ }^{20}$

\footnotetext{
I8 POSADA CARBÓ Eduardo. "¿Libertad, libertinaje, tiranía? La prensa bajo el olimpo radical en Colombia, I863- I885". En Sierra Mejía, Rubén. El radicalismo colombiano del siglo xIx. (Bogotá: Universidad Nacional de Colombia, Bogotá, 2006) , pág. I 5 I.

19 El Baluarte, No. I, Bogotá. Julio 4 de 1830

20 El Sastre, No. I, Bogotá, Noviembre 10 de 1839,pág. I
} 
Además del acento popular en los contenidos, en el discurso de la prensa granadina sobresalen otros elementos constitutivos. Uno de ellos, profundamente emotivo, es la violencia inherente a las referencias que aludían a los adversarios políticos y sociales. En tal sentido, la prensa proyectó un ideal moral de sujeto y de colectividad que fue tanto republicano -liberal- como católico.

Dime, Duende tonto y bobo,

¿Cual fue la maldita vieja

que le contó que era oveja

la de la historia del lobo?

Sabrás pues, gran majadero,

sin instrucción ni talento,

que echaste a perder el cuento

del lobo con el cordero. ${ }^{21}$

De modo que la prensa neogranadina desempeñó tres funciones en el periodo estudiado. De una parte se constituyó como un mecanismo amplificador del caos; en otro sentido, fue un instrumento aleccionador de la población, a través de una pedagogía republicana que hacía exaltación de las leyes. Finalmente, la prensa neogranadina se convirtió en un tribunal de apelaciones de última instancia; se trataba del tribunal de la opinión pública que emitía los últimos fallos. Incluía los alegatos, las pruebas y las quejas y reprimendas.

\section{La prensa como amplificador del caos}

En las ciudades andinas, pero especialmente en Bogotá, ocurría una disputa que oponía a la filosofía liberal de estirpe utilitarista con el misticismo tomista. Generaciones enteras de abogados y teólogos fueron educados en un ambiente intelectual dominado por las orientaciones que impartían las órdenes sacerdotales de los colegios mayores. En opinión de los teólogos, la filosofía liberal debería ser aborrecida como si fuera un anatema. De manera que la reforma educativa que emprendió Francisco de Paula Santander, tendiente a implementar cursos de filosofía benthamista en las aulas de derecho, se vio enfrentada a las posturas reaccionarias del clero. $^{22}$

Un breve vistazo al panorama cultural neogranadino, nos muestra un mundo anti intelectual, según la idea del filósofo Rubén Jaramillo Vélez, era el producto de una "Bohemia cachaca y neotomismo, cultura señorial y simulación [que] no parecen ser propiamente los elementos propiciadores de un

21 El Cristiano Errante, Bogotá, No. 23, enero 2 de 1847, pág. 3.

22 La dimensión alcanzada por la disputa en torno a los textos de Jeremy Bentham, llevó a pensar que el clero antioqueño y bogotano, preparaba una rebelión contra el gobierno de Francisco de Paula Santander. 
clima en el cual la filosofía se hiciera posible y necesaria". ${ }^{23}$ La cultura cachaca a la que se refiere el filósofo Rubén Jaramillo está inspirada en el personaje bogotano del cachaco. Florentino González, periodista y político liberal definió el origen de este tipo bogotano en su periódico homónimo, en la década de 1830, como el estudiante de los colegios mayores que dejó las aulas de derecho y salió en apoyo de la revolución independentista. La primera alusión al cachaco está impregnada del ímpetu juvenil que, posteriormente se asoció a los personajes de élite urbana que compartían la sofisticación en el vestir, la preferencia por las letras y la práctica del derecho. De modo que los cachacos constituían la imagen por antonomasia del civilismo.

Sin duda, la Bogotá del siglo XIX más que otras ciudades colombianas, puede ser catalogada con las características de la ciudad letrada que, según Ángel Rama, necesitaba del apoyo de letrados en la definición de una burocracia estatal y en la realización de proyectos de evangelización. Como ciudad de servicios, Bogotá ofrecía a sus habitantes la administración de los ritos religiosos y establecimientos educativos para formar futuros teólogos y abogados. Reitera Rama que "el corpus de leyes, códigos, acrecentado aún más desde la Independencia, concedió un puesto destacado al conjunto de abogados, escribanos, escribientes y burócratas de la administración". ${ }^{24}$

El derecho definió como ninguna otra profesión la personalidad urbana de muchos bogotanos y en general de los colombianos pertenecientes a la élite. La Nueva Granada fue proyectada por y para los abogados; aún en corrientes partidistas antitéticas, los arquitectos de la República fueron abogados o estudiaron derecho. Este fenómeno es poco estudiado por la historiografía colombiana y tan solo se revelan unas cuantas pistas para descifrar su origen, la más plausible consiste en afirmar que la eliminación física de los altos mandos colombianos, durante la guerra de pacificación española de 1816, dejó al país sin los mejores líderes militares como Antonio Baraya lo que permitió que el control del ejército quedara en manos de los oficiales venezolanos. De modo que fueron los líderes civilistas como Francisco de Paula Santander, conocido como el "Hombre de las Leyes" y su rival político Ignacio de Márquez, ambos, los impulsores en la redacción de códigos y leyes mediante las cuales se trazó el semblante civilista en la historia política de Colombia.

En tanto, el grueso de la población cegada por la especulación religiosa y por los avatares de las relaciones pragmáticas, recibía información tamizada a través de la apariencia del rumor y de la simulación; era así como la mayoría de las personas descifraban los misterios de un mundo todavía aldeano.

El rumor y la simulación se sustentaban en fórmulas de la retórica, falacias argumentativas e imprecisiones circunstanciales que hacían que la balanza del juicio de los neogranadinos se inclinara a favor de las opiniones de la prensa. Pero sin duda fue el primero, es decir el rumor, el amplificador del caos. ${ }^{25}$

23 Jaramillo Vélez Rubén. "La filosofía y la provincia. Homenaje a los pioneros del pensamiento moderno en Colombia". Aquelarre, No. 25, Vol. 12, (20I3): pág. 208.

24 RAMA Ángel, La ciudad letrada (Santiago: Tajamar Editores, 2004), pág. 72.

25 Señala puntualmente María Teresa Uribe de Hincapié: "Pero quizá más que las publicaciones periódicas u otros documentos escritos fue el rumor, las historias contadas de boca en boca, de generación en generación, lo que se relataba en los hogares 
Dos páginas sueltas proporcionan datos para comprender el fenómeno. El hijo de Bogotá, alertaba del alcance de los mecanismos que empleaban el rumor y el chisme para desestabilizar a la sociedad urbana. Enfatizaba con indignación cómo los bogotanos, al igual que lo ocurrido en I826, prestaban oídos a patrañas sin fundamento. En aquel año corrió el rumor según el cual el diablo saltaba en las cúspides de los cerros tutelares de la ciudad, prestos, los bogotanos salían a los patios de sus casas con anteojos para ver al demonio dar saltos de fuego. De la misma manera que en la década de 1830, el público prestaba oídos a cualquier tipo de habladuría sobre el gobierno, a posibles rebeliones de clérigos y a sublevaciones del ejército.

En la misma década de los veinte, la prensa bogotana exaltó un episodio de intolerancia religiosa y de anti-intelectualismo. En I824, en Bogotá se presentó la obra de teatro el fanatismo o Mahoma, causando gran alboroto en la ciudad. Aunque no se trataba de un montaje teatral que inspirara una crítica al catolicismo, un grupo de jóvenes del Colegio de San Bartolomé pensó que sí lo era, y la situación de salió de control; lo curioso del asunto es que el periódico, en el que se reseñó este asunto embarazoso, se escandalizaba no de la actitud de los jóvenes sino de la compañía teatral por fomentar imágenes y obras de herejes.

Esta misma situación en la que cundía el rumor y el chisme se presentó en los albores de la Guerra de los Supremos: "Los rumores más absurdos circulan cada día y son inventados y propalados por los aficionados al bochinche, que no encuentran otro medio más seguro de contribuir con su contingente a favor del desorden". ${ }^{6}$ La falta de precisión de la información también se dio al inicio de la guerra convirtiéndose en un aspecto invariable en la prensa neogranadina, así lo manifestó en I 840 El Observador de Bogotá. El periódico argumentaba que eran falsas las noticias que decían, que a inicios de enero de ese año, los pastusos se habían apoderado de tres comarcas controladas por las fuerzas del gobierno de Bogotá. La falsedad con la que se presentaban las notas periodísticas en otros medios escritos le permitía a El Observador, criticar la forma en que aquellos obtenían la información. Este periódico se quejaba de la calidad de los informantes y de los contenidos de la prensa oficial. ${ }^{27}$

En medio de la guerra, la prensa en el sur del país aducía que Bogotá se constituía como el centro de la desinformación, pues según la Voz del Sur, "La capital de la República es siempre el foco de los partidos y el taller de los medios e instrumentos que ellos fabrican para conseguir cada uno su fin [...]".28 Esta publicación caleña, surgía para controvertir a La Bandera Nacional, al Correo y al Argos, todos periódicos bogotanos. Además, en este juego de las vindictas periodísticas entró a terciar El Observador de Bogotá. Las páginas de La Voz aludían a las interpretaciones erróneas del

o en los vecindarios, lo que se comentaba en las tertulias, en las esquinas o en los atrios de las iglesias. Estas memorias orales permitieron la reconfiguración de las poéticas y las dramáticas, convocaron el miedo, la compasión y el terror y eso que la historiografía colombiana ha llamado «los odios heredados»; lo cual permitió que pervivieran, reproduciéndose, ampliándose y resignificándose relatos y memorias cuyas huellas llegan hasta el presente". María Teresa Uribe de Hincapié. Un retrato fragmentado. Ensayos sobre la vida social, económica y política de Colombia -siglos xIx y Xx. (Medellín: La Carreta, 20 I I), pág. I42.

26 Anónimo. Guerra de Chispas. (s.d).

27 El Observador, Bogotá, No. 18, 19 de enero de 1840, pág.72.

28 La Voz del Sur, Cali, No. 5, enero 19 de 1840, pág.3. 
código penal, que de acuerdo a la prensa de Bogotá, pretendían poner en cintura a los facciosos; La Voz comprometía el juicio de los bogotanos puesto que las leyes no se aplicaban en justicia de los colombianos en el sur del país.

La simulación consistió en hacer pasar asuntos superfluos como verdaderamente importantes, también enmascarando la realidad con la mentira o propagando mitos. Valdría la pena señalar, como lo advirtió Ernst Cassirer, que este tipo de fenómenos de orden mítico -la simulación o la especulación-, inciden fuertemente en la política, especialmente durante los momentos de la historia occidental en los que se reconfigura un orden social basado en la razón humana, de manera que la razón se ve inmovilizada por la persistencia de las formas de pensamiento mediante las cuales se reproduce el mito. ${ }^{29}$

Las circunstancias en las que se desarrollaron el rumor y la simulación consistieron en denotar, en la prensa y en los panfletos, algunas estrategias retóricas. Por ejemplo, fue frecuente leer encabezados y columnas con imprecisiones y falacias argumentativas como: Se dice que, en algún lugar, alguien; en cuanto a las circunstancias se escribía a través de: ocurrió en un sitio indeterminado, en la oscuridad de la noche, en la calle, en la plaza. Las víctimas generalmente fueron las mujeres y hombres indefensos, las personas humildes y personas con dignidades eclesiásticas o civiles.

El caso más destacado de la prensa sensacionalista en la Nueva Granada fue el del médico José Félix Merizalde, este personaje fundador de la prensa amarillista en Colombia, no ahorró tinta para descalificar a sus enemigos y ellos también emplearon la pluma para someterlo al escarnio público:

[...]No hay en Bogotá un solo suceso desagradable en el que no haya tenido parte. Hipócrita refinado, se mete de santurrón para engañar a la gente juiciosa y timorata y encubrir sus vicios y picardijuelas. Famosos petardista, no hay persona a quien no le haya entrampeado, ni libro de deudas en donde no este escrito su nombre. Vano y miserable ostenta un alto origen, siendo hijo sacrílego y de una prostituta cuarterona $[\ldots]^{30}$

Los publicistas granadinos emplearon sus columnas para desacreditar y atacar a sus colegas. La contundencia de las palabras contra Florentino González, director de El Cachaco no se hizo esperar, puesto que de acuerdo con su detractor, El Cachaco escribía con informaciones imprecisas: "Aprenda U. señor, a respetar a sus conciudadanos. Tenga $U$. ideas más exactas de la virtud, o a lo menos de la moral, para no hacer objeto de su saña, lo que debiera elogiarse aún en un pueblo bárbaro, y sepa

29 Precisa Cassirer: "[...] En todos los momentos de la vida social del hombre, las fuerzas racionales que resisten al resurgimiento de las viejas concepciones míticas, pierden la seguridad en sí mismas. En estos momentos, se presenta de nuevo la ocasión del mito. Pues el mito no ha sido realmente derrotado ni subyugado. Sigue siempre ahí, acechando en la tiniebla, esperando su hora y su oportunidad. Esta hora se presenta en cuanto los demás poderes de vinculación de la vida social pierden su fuerza, por una razón u otra, y no pueden combatir ya los demoniacos poderes míticos". Ernst Cassirer. El mito del Estado. (Bogotá: FCE, 1999): pág. 331.

30 J. F. ÁLVARES Manuelo y Socios. Los Díceres de Bogotá. Cartagena, Imprenta Tormentaria de J.M. Angulo, I834. 
que no le teme". ${ }^{3 !}$ En otro texto se hizo evidente que la simulación y la deformación de la verdad sembraba el caos y el miedo entre los lectores. "Exhortamos al Cachaco a ser menos apasionado y exaltado en sus escritos que empiezan a ser el escarnio de todos sus lectores, por sus injurias y su procacidad: así lo deseamos en obsequio de la paz y del orden".32

En otro caso, en la ciudad de Zipaquirá, se había cometido un asesinato de una mujer y aparecieron unas hojas sueltas en las que la nota periodística estaba salpicada de profundas incongruencias: "[... .] dígase pues si tanto interés se tiene por la moral pública, y en obsequio de la verdad, y de una manera franca y explícita, en dónde fue que se cometió el delito, y por qué personas [...]".33 En síntesis, los neogranadinos vieron como fluía una prensa que tendió a la deformación de la realidad y a pintar un panorama de caos, generalmente asociado a los momentos de la crisis política y social del país.

\section{La prensa y la pedagogía civil}

El predominio del derecho en la vida pública de Colombia, sobre otros ámbitos como la carrera militar, puede ser analizado desde otra óptica en la que interesa el manejo de la prensa. Es así como se argumenta que, los ideólogos del derecho liberal vieron en la prensa de Nueva Granada un instrumento eficaz para divulgar nuevos valores.

Ante el inminente peligro que representaba la insubordinación de las castas sociales, la élite transformó la prensa para divulgar un acuerdo respecto a la idea de orden social que debería seguir imperando. Los sujetos sociales marginados aparecieron en las notas de los periódicos granadinos, muchas veces caracterizados por el error y el vicio.

Durante la era republicana, el asunto de la libertad de prensa surtió insumos para entablar discusiones muy fuertes. De una parte, la libertad de imprenta había sido un derecho que se reclamó tras la independencia; también se aspiró a este derecho cuando se asoció a las medidas tendientes a incrementar la lectura pública de la prensa en la población granadina. No obstante, existieron trabas al trabajo de los publicistas granadinos que recortaban sus derechos.

La prensa fue objeto de regulación por parte de los gobiernos de Nueva Granada y a la vez fue un instrumento para difundir ideas en torno a la ley, a la justicia y al Estado. Dado que el arribo de la imprenta al Nuevo Reino de Granada fue tardío, no existió una cultura de la prensa en el virreinato hasta el último tercio del siglo XVIII, es por ello que la prensa de la época colonial se movió entre la crítica y la censura; ${ }^{34}$ sin embargo, fue más sentido el interés del gobierno de la colonia por inspec-

31 J.J. Gori. Al Cachaco de Bogotá. Bogotá, Imprenta de Salazar, I833.

32 Varios individuos de la Guardia Nacional. Contestación al Cachaco o Catarro de Bogotá. Cartagena, imprenta de los herederos de J. A. Calvo, 28 de nov. 1833.

33 Anónimo, "Dos palabras al autor del folleto Suceso espantoso" (s.d)

34 Silva, Renán. Prensa y revolución a finales del siglo xVIII. Contribución a un análisis de la ideología de la Independencia nacional. (Medellín: La Carreta, 2004), pág. 44. 
cionar el quehacer de los publicistas, de modo que los lectores del Santo Oficio cotejaban que los escritos no contradijeran los evangelios.

La legislación reguladora del oficio de los periodistas y ordenadora de la libertad de imprenta se remonta, durante la República, a ley $3^{a}$ expedida en septiembre I 82 I. Esta ley colombiana organizó la extensión de la libertad de imprenta y sus abusos. ${ }^{35}$ También facultaba a todo colombiano a imprimir sus pensamientos libremente sin censura previa; no obstante, la autoridad judicial podría calificar los abusos en los impresos en tercer, segundo y primer grado de gravedad, también los podría catalogar como subversivos, sediciosos, obscenos o contarios a las buenas costumbres y de acuerdo con ello, las penas podían ir desde el decomiso de los escritos, hasta la mutilación de las publicaciones y la devolución del dinero al comprador. En cuanto a los autores, el abuso en la libertad de imprenta conllevaba fijar corresponsabilidades entre el autor, el editor y el impresor; para tal fin la ley establecía, como requisito previo para cualquier publicación la firma del autor, aún que el escrito tuviese una naturaleza anónima. En mayo de 1838 se enmendó la ley de I82I y se arregló de acuerdo con lo establecido en el código penal neogranadino de 1837, que dispuso la suspensión del cargo hasta por cuatro años al funcionario del Estado que impidiera, a cualquier ciudadano, imprimir libremente sus escritos.

El código penal establecía penas de multas y suspensión de los derechos civiles y políticos, incluido el arresto a quien violara la ley de libertad de imprenta. Las multas también podían recaer en quienes reimprimieran escritos que ya hubiesen sido decomisados o en aquellos que reimprimieran documentos propios del Estado. Otro tipo de violaciones del autor, editor o impresor se tipificaban como delitos de injuria y calumnia y daban lugar a penas hasta dos años de prisión y multas hasta de 50 pesos.

Una polémica se libró por la libertad de imprenta en el año de 1837 que involucró a La Bandera, El Argos y El Constitucional de Cundinamarca; este último insertó una noticia proveniente del Liberal de Caracas y los dos primeros se enfrentaron por determinar la naturaleza estatal o privada del Constitucional y la concomitante extensión de la censura previa a la prensa oficial. ${ }^{36}$

Un caso puntual de censura de prensa en 1842 le ocurrió al impresor Nicolás Gómez. Gómez había reformado su imprenta por lo que fue acusado por la jefatura política de la ciudad de Bogotá. La acusación del jefe político estaba sustentada en la ley de policía que castigaba la apertura de una nueva imprenta sin el permiso de la autoridad. Así, la jefatura política interpretó que Gómez había instalado una nueva imprenta y lo sancionó con una pena de dos meses de prisión y a pagar una multa de 100 pesos. Finalmente, Gómez apeló cuatro días después y fue puesto en libertad y no se le cobró multa alguna. ${ }^{37}$

\footnotetext{
35 Recopilación de Leyes de la Nueva Granada. Formada y publicada en cumplimiento de la Ley de 4 de mayo de I 843 por comisión del poder ejecutivo. Bogotá: Lino de Pombo, Imprenta de Zoilo Salazar, febrero de I845, págs. 46 I-464.

36 El Argos, Bogotá, No. 4, diciembre 17 de 1837, pág. 16.

37 El Constitucional de Cundinamarca, Bogotá, No.44, junio 26 de 1842, pág. 175.
} 
Como instrumento pedagógico, la prensa -especialmente la oficial- gozó de alta estima. Entonces, la prensa reprodujo las leyes, decretos, circulares, epístolas, censos y estadísticas que produjo el Estado. Incluso, algunos periódicos contenían fragmentos narrativos de la gesta independentista y apartes biográficos de los próceres.

En los periódicos granadinos la tinta se derramó al escribir sobre asuntos de interés general: fueron frecuentes notas sobre las sociedades de amigos del país, avances agrícolas e industriales, alusiones a historias bíblicas, episodios de mitos clásicos, avisos publicitarios de los boticarios y libreros y necrologías, entre otros temas.

Los articulistas independientes aprendieron que la prensa era el espacio para expresar sus ideas acerca del funcionamiento del Estado y de la política. Por tanto, la prensa granadina fue el reflejo del panorama político del país, que era en sustancia fragmentado y escindido, pero a la vez fue un campo de batalla de los idearios políticos en conflicto.

La prensa popular exponía algunos principios democráticos, tal como la confianza en el parlamento, gestor de las leyes, que podría reversar la situación de la producción tabacalera en I850: "El Congreso, solo el Congreso puede poner remedio a todos los males [la crisis en los precios del tabaco]". ${ }^{38}$ Otros medios escritos aludían al control de problemas sociales como la prostitución y la vagancia. Con el título de "Moralidad", el gobernador de la provincia de Bogotá, informaba en I 843 en El Constitucional de Cundinamarca que, "los jefes de policía tienen las suficientes facultades para enfrentar el vicio y estimular la virtud $[\ldots]$ los jueces $[\ldots]$ han sentenciado multitud de ladrones $[\ldots]$ la pena de vergüenza pública se ha ejecutado sin consideración alguna $[\ldots]$ y por primera vez se ha enviado al fomento de nuevas poblaciones a sesenta mujeres que públicamente hacían ostentación de su mala conducta." 39

Una de las funciones que se abrogaron algunos periódicos granadinos fue la de aleccionar a la población, de acuerdo al correcto sentido del republicanismo y en pos de cimentar la opinión pública. Un periódico bogotano resumió esta función: "Así son hechas las leyes de la República y los gobiernos constitucionales, por que como en ellos la opinión popular gobierno y no el capricho de los déspotas, es preciso influir sobre esta opinión [...]" continuaba argumentando que "más el buen sentido en los países en que el gobierno representativo ha echado raíces no se deja alucinar, oye a las partes y juzga por sí mismo."40

Algunos periódicos se constituían solo en oposición a otras publicaciones. Este fue el caso del periódico panfletario El Astrolabio Bogotano que enfiló su pluma contra La Estrella Nacional. El Astrolabio comentó a los bogotanos en 1836 los fundamentos doctrinarios del periodismo que practicaba La Estrella y los catalogó de ser la causa del miedo en sus lectores; invocando al público para establecer acuerdos en torno a los vicios de su rival, El Astrolabio destacaba las cualidades de los antiguos romanos

38 El Cañón. Bogotá, No. I, enero 13 de 1850, pág.2.

39 El Constitucional de Cundinamarca, Bogotá, No. I04, septiembre 15 de 1843, págs. I I0-1 I I.

40 El Censor, No. I, Bogotá, octubre 20, I839, pág. I. 
inspiradas en el triunfo y el valor sobre las desgracias, enfatizaba que "la educación, el empleo de las leyes, las costumbres hacen adquirir valor. Así es que el gobierno y las leyes pueden hacer a un pueblo cobarde o animoso"; 41 por el contrario, establecía analogías que relacionaron el miedo, de acuerdo con los "movimientos falsos del alma", los mismos movimientos que empujaban la escritura de los publicistas de La Estrella. Continuaba afirmando que consecuencia de los artículos de La Estrella se propagó una sensación de miedo, a perder la fama y la fortuna, en la Nueva Granada. Por tanto, a lo largo de sus páginas, se alabaron los valores como la prudencia, la dignidad y la libertad republicana, en El Astrolabio se hizo una pedagogía cívica que enseñó algunas rutas del republicanismo.

La pedagogía también recaía en guiar a los granadinos en la sintonía de los cambios que llevaban a la formación de las democracias liberales en Europa, así El Constitucional de Cundinamarca, periódico estatal, se justificaba ante acusaciones que lo señalaban por no insertar notas del extranjero en sus columnas y de este modo malgastar recursos públicos, a lo que respondía que "en el día hacemos parte de la sociedad de las naciones: sus progresos, sus catástrofes, sus vicisitudes, nos interesan. Los que estudian las ciencia social, tienen un curso completo en las alteraciones de la política extranjera, y todo suceso importante que en ella ocurre, se liga con un principio fundamental y nos instruye de la política contemporánea". ${ }^{2}$

\section{La prensa, un nuevo estrado judicial}

La prensa neogranadina aleccionaba a los ciudadanos sobre las bondades o vicios de la justicia republicana que se estaba implementando, bien fuera a través de casos ficticios o poniendo énfasis en casos puntuales y bien conocidos por el público. Un ejemplo de un hecho contra-factual lo presenta el semanario bogotano El Granadino, haciendo mención a los proyectos de reforma de la justicia, argumentaba que en la administración de la cárcel "la responsabilidad del alcaide por la fuga de un preso debería ser muy severa, cuando generalmente ocurre por su abandono o descuido". ${ }^{3}$ Luego, el interés del publicista era el de incitar al acuerdo entre el público en torno a la idea de los juicios por jurados, así lo señaló, "si el juicio por jurados parece una institución digna de elogios como institución política, más bien que como institución judicial; si se cree que este establecimiento es muy a propósito para impedir la tiranía de los jueces". ${ }^{44}$ Números posteriores del mismo semanario, presentaron al público acusaciones con exposición de los motivos, conforme ocurría en un alegato de algún fiscal. El asunto que trataba era el nombramiento del obispo de Cartagena, en cuya designación intervino el poder ejecutivo durante el mandato de Simón Bolívar desconociendo el Patronato; la ratificación hecha por el Vaticano recaía en el mismo vacío jurídico, por lo que el semanario puso en duda la legitimidad del cargo eclesiástico años después. ${ }^{45}$

41 El Astrolabio Bogotano, No. I, Bogotá, enero 17 de 1836: pág. I.

42 El Constitucional de Cundinamarca, Bogotá, No.15, enero 17 de 1832, pág. 67.

43 El Granadino, Bogotá, No. 8, noviembre 20 de 1831, pág. 49.

44 El Granadino, Bogotá, No. 8, noviembre 20 de I83।, pág. 49.

45 El Granadino, Bogotá, No. II, diciembre II de I83।, pág. 60. 
El síndico del hospital de caridad de Bogotá, empleó la prensa oficial para notificar a los ciudadanos que tenían deudas por pagarle a la institución al advertirles que, cansado de invitarlos cordialmente a que pagaran sus deudas, publicaría sus nombres en la prensa y procedería también a demandarlos ante la justicia de Nueva Granada. Esta era una práctica a la que acudían por igual los directores y los editores de la prensa. ${ }^{46}$

La prensa fue a la vez juez y parte, estrado y jurado en las cuestiones de honor que resultaban injustas para los neogranadinos. Los usuarios de este tipo singular de justicia, basada en la opinión pública, elevaron sus pretensiones en forma de pleitos para resolverse en última instancia en las publicaciones periódicas. Las causas interpuestas no tenían tiempos determinados, solo la oportunidad de hacer una vindicta personal; los casos elevados a la prensa fueron algunos que habían sido fallados sin el recurso de apelación por la justicia ordinaria. Así, muchos granadinos descubrieron que la prensa, los libelos y los folletos podían tener las mismas funciones de un juzgado. Este tipo de función de la prensa se ponía en operación para reivindicar el honor y la dignidad de aquellos acusados y sentenciados en la realidad jurídica neogranadina. El siguiente pasaje de la prensa neogranadina se escribió con el ánimo de hacer que los facciosos, durante la Guerra de los Supremos, reconocieran el valor de la opinión pública que se hacía explícito en la prensa oficial:

El pueblo ilustrado, depositario de las leyes y de los archivos del honor, administrador de la sanción moral, forma un tribunal supremo que decide sobre las causas y sobre las personas. La publicidad de las negocios pone a este tribunal es estado de reunir las pruebas y juzgar, y por la libertad de la imprenta pronuncia y hace ejecutar su sentencia. ${ }^{47}$

La forma de operar este estrado extra-jurídico, consistió en imitar el procedimiento y los tiempos en que se desarrollaba el proceso jurídico de la justicia ordinaria. De manera que el juicio iniciaba con una demanda, continuaba con los alegatos y posteriormente se emitía una sentencia. Los casos que se presentan en esta sección incluyeron vindicaciones por el honor, incluso después de la muerte, como lo ocurrido a los militares implicados en la rebelión de I833. Sus defensores publicaron "vindictas" en pasquines a través de las cuales intentaron limpiar el buen nombre de los militares que fueron ejecutados por los delitos de sedición y traición.

A Vicente Nariño, el hijo del precursor Antonio Nariño, se le acusó en un artículo del periódico bogotano El Día de enero de 1849, de no cumplir sus deberes como bibliotecario en la Biblioteca Nacional; Nariño prefirió no guardar silencio, por lo que recurrió al mismo medio periodístico para salvar su honor de tales acusaciones. Las denuncias hechas en El Día, en contra de Nariño, tenían que ver con la inutilidad de que, según el articulista y denunciante, representaba una biblioteca vacía y sin algún tipo de organización archivística. Nariño, tocado en su dignidad, procedió a desmentir los dos cargos que se le imputaron en la prensa. Los argumentos de Nariño, ante la acusación de desorgani-

46 La Gaceta de Cundinamarca, Bogotá, No. 26, diciembre 30 de 1837, pág. I 6.

47 Anónimo. Perniciosos efectos de la cólera. Bogotá: Imprenta de Nicomedes Lora, 1838. 
zación documental, desestimaron la demanda pues y afirmó que "los impresos se hallan en el arreglo que estoy obligado a darles". Frente al segundo cargo, la aparente ineficacia de la biblioteca, indicó con precisión que "no es menos escaso de razón y justicia". En sus alegatos en la prensa, Nariño empleó la violencia de las palabras. Arguyó que su honor había quedado en entre dicho, pues los articulistas se dedicaban a su labor "destruyendo con el solo trabajo de escribir un renglón, reputaciones bien adquiridas y conservadas con austeridad y constancia". ${ }^{48}$ Por último solicitó del editor la publicación de los alegatos en el periódico para poder iniciar su defensa.

Los motivos no necesariamente tenían que ver con cuestiones del honor o la fama, algunas veces la prensa registró casos como la falsificación de moneda macuquina, durante la década de 1830. También, los granadinos vieron cómo, en la prensa, se tejieron pleitos por cosas minúsculas como la calidad de fósforos que compraban los bogotanos:

-Otro desagravio. ¡Viva la imprenta! Criticóse en este diario la venta de malos fósforos en la tienda del señor García y fue santo remedio para que los regalase las cosas perdidas y hoy se hallan allí de venta fósforos superiores. Honor a la calidad de nuestro amigo y parroquiano. Si así respetaran todos, la tribuna tipográfica ¡Cuántos defectos hallaríanse ya corregidos!... ${ }^{49}$

No siempre las acusaciones trataban sobre hechos sin alguna importancia como las críticas que sufrió Nariño. Durante la guerra se puso en marcha un conjunto de leyes que, por su aplicación extraordinariamente rápida, caían por igual en la condena de culpables e inocentes. Algunos abogados y jueces fueron acusados de ayudar a los facciosos durante la Guerra de los Supremos, a estos funcionarios del sistema judicial neogranadino les fueron suspendidas sus funciones y sus bienes fueron decomisados por el bando gobiernista de la guerra. Incluso, las discusiones jurídicas se trasladaron al mundo de la prensa, muchos jueces fueron el blanco de represalias del gobierno y debieron manifestarse en los periódicos y en los pasquines neogranadinos; un juez publicó lo siguiente: "sobre todo los que por desgracia ejercemos el ministerio del juez, somos constantemente blanco de las diatribas de cuantos litigantes han visto". ${ }^{0}$ Un balance de la prensa neogranadina, la que fue asumida como un estrado judicial, ofrece un panorama de desconfianzas mutuas de los ciudadanos respecto al aparato de justicia recién implementado. También revela el empleo de un lenguaje periodístico que intentó incidir directamente en la opinión pública a través de la simulación y un conjunto de juegos retóricos.

48 El Día, Bogotá, No. 581, enero 17 de 1849, pág. 3.

49 Plus-café, Bogotá, No. I8, julio 30 de 1849.

50 El folleto fue publicado por tres jueces que fueron perseguidos por los ministeriales en el transcurso de la Guerra de los Supremos, José Ángel Lastra, José María de la Torre y Ramón Ortiz. Vindicación, Bogotá: Imprenta de Nicomedes Lora, 1836. 


\title{
Conclusión
}

A la luz de las evidencias históricas presentadas, se puede hacer un balance en el que la prensa neogranadina fue, un instrumento de divulgación de nuevos valores, para la sociedad en la que las instituciones republicanas se estaban hasta ahora formando. También fue asumida como un elemento mediante el cual se podía deformar la realidad, de manera que fueron descalificados muchos sujetos o situaciones; estas acciones no fueron irreflexivas sino que expresaron una actitud consciente de los publicistas por incidir en el público, de acuerdo a sus intereses particulares. Para ello emplearon tres planos, la prensa como deformadora de la realidad, la prensa como una plataforma de la pedagogía civil, y la prensa granadina como un gran estrado judicial.

Respecto al primer asunto, la información mediante la cual los granadinos se percataban del transcurrir del país y del exterior, la imagen de la realidad fue permeada por el sensacionalismo y la simulación. Las intenciones de tal ejercicio de simulación fueron las de apoyar la proyección de leyes de control social y político. Generalmente, una noticia sobre un evento catastrófico del orden social, económico o político iba acompañada por un exordio que aclaraba, desmentía o afirmaba el contenido de la información y solicitaba alguna toma de medida por parte del gobierno.

El segundo ámbito que desempeñó la prensa fue el de divulgar los valores civilistas. Los articulistas neogranadinos tenían fuertes lazos con las facciones partidistas que urgían la implementación de las instituciones republicanas. La constitución de 1832 y la serie leyes orgánicas vinieron a acompañar el quehacer de los articulistas, en torno a la libertad de prensa. Así, el trabajo de la prensa fue estimulado por los gobiernos pero al tiempo lo limitaron con la censura.

El tercer plano de la prensa manejado en este ensayo es el menos inquietante para la historiografía especializada. La prensa fue para muchos granadinos una oportunidad de alcanzar la justicia que no habían logrado en el sistema judicial recién instaurado. Como otros muchos estrados judiciales, la prensa contó con jurados que fueron los lectores de Nueva Granada. Las víctimas alegaron sus pretensiones, los abogados realizaron descargos y al final todos pedían que la sentencia de última instancia les fuera favorable.

\section{Fuentes Documentales y Bibliografía}

\section{Fuentes primarias y periódicos}

\section{Periódicos}

\author{
El Argos [1834-37] \\ El Astrolabio Bogotano 1836] \\ El Baluarte [1830] \\ El Cachaco Bogotano [1833-34]
}


El Calentano [1834]

El Cañón [1850]

El Censor [1839]

El Constitucional de Cundinamarca [1837-42]

El Cristiano Errante [1847]

El Día [1849]

El Duende [s.d.]

El Gallardete de la Bandera Nacional i la Bandera Negra [ 837$]$

El Granadino [1831]

El Observador [1840]

El Pararrayo [1834]

El Repertorio [1853]

El Sastre [1839]

La Gaceta de la Nueva Granada [1838]

La Prensa Bogotana [1833-1834]

La Voz del Sur [1840]

Los Díceres [1834]

Plus-café [1849]

\section{Leyes y libelos}

Anónimo, "Dos palabras al autor del folleto Suceso espantoso" (s.d)

Anónimo. Guerra de Chispas. (s.d).

Anónimo. Perniciosos efectos de la cólera. (Bogotá: Imprenta de Nicomedes Lora, 1838)

J. F. ÁLVARES Manuelo y Socios. Los Díceres de Bogotá. Cartagena, Imprenta Tormentaria de J.M. Angulo, I834

PEDRO ALCÁNTARA Herrán. Revolución de ideas, Bogotá, Imprenta de N. Gómez, 1839.

Recopilación de Leyes de la Nueva Granada. Formada y publicada en cumplimiento de la Ley de 4 de mayo de 1843 por comisión del poder ejecutivo. Bogotá: Lino de Pombo, Imprenta de Zoilo Salazar, febrero de 1845.

Varios individuos de la Guardia Nacional. Contestación al Cachaco o Catarro de Bogotá. Cartagena, imprenta de los herederos de J. A. Calvo, 28 de nov. 1833. 


\section{Fuentes secundarias}

BUSHNELL, David. Ensayos de historia política de Colombia, siglos xIx y xx. Medellín: La Carreta, 2005.

CASSIRER, Ernst. El mito del Estado. Bogotá: FCE, 1996.

CHIRIAMONTE, José Carlos, Carlos Marichal y Aimer Granados, (compiladores). Crear la nación. Los nombres de los países de América Latina. Buenos Aires: Editorial Sudamericana, 2008.

COLMENARES, Germán. Partidos políticos y clases sociales. Bogotá: Ediciones los comuneros, 1984.

DELPAR, Helen. Rojos contra azules. El partido liberal en la política colombiana, 1863 - 1899. Bogotá: Procultura, 1994.

MOLINA Gerardo, Las ideas liberales en Colombia, I849-1914. Tomo I, Bogotá: Universidad Nacional de Colombia, 1970.

GONZÁLEZ E, Fernán. Partidos, guerras e iglesia en la construcción del Estado Nación en Colombia (1 830-1900). Medellín: La Carreta, 2006.

JARAMILLO VÉLEZ, Rubén. "La filosofía y la provincia. Homenaje a los pioneros del pensamiento moderno en Colombia”. Aquelarre, No. 25, Vol. 12, (2013)

LAURENT, Muriel. Contrabando en Colombia en el siglo XIX. Prácticas y discursos de resistencia y reproducción. Bogotá: Uniandes, 2008.

MEISEL ROCA, Adolfo y María Teresa Ramírez. Economía colombiana del siglo XIX. Bogotá: FCE / Banco de la República, 2010

PARADA GARCÍA, Gilberto Enrique. "La retórica del miedo en la prensa bogotana de 1834". Historia Critica 36 (Jul-dic, 2008), págs. 58-81.

PINTO BERNAL, José Joaquín. "Entre Colonia y República. Fiscalidad en Ecuador, Colombia y Venezuela, I7801845", Tesis doctoral en historia. Bogotá: Universidad Nacional de Colombia, 2014.

POSADA CARBÓ, Eduardo. "Libertad, libertinaje, tiranía? La prensa bajo el olimpo radical en Colombia, I863I885”. En: Sierra Mejía, Rubén. El radicalismo colombiano del siglo XIx. Bogotá: Universidad Nacional de Colombia, Bogotá, 2006, págs. 147-166.

RAMA, Ángel. La ciudad letrada. Santiago: Tajamar Editores, 2004.

SILVA, Renán. Prensa y revolución a finales del siglo XVIII. Contribución a un análisis de la formación de la ideología de la Independencia nacional. Medellín: La Carreta: 2004.

TORRES TORRENTE, Bernandino. Sombras y misterios, o los embozados. Bogotá: Imprenta de Francisco Torres Amaya, 1859.

TOVAR PINZÓN, Hermes. La Batalla de los sentidos. Infidelidad, adulterio y concubinato a fines de la colonia. Bogotá: Uniandes, 2012.

URIBE DE HINCAPIÉ, María Teresa. Un retrato fragmentado. Ensayos sobre la vida social, económica y política de Colombia -siglos XIx y Xx. Medellín: La Carreta, 201 I. 